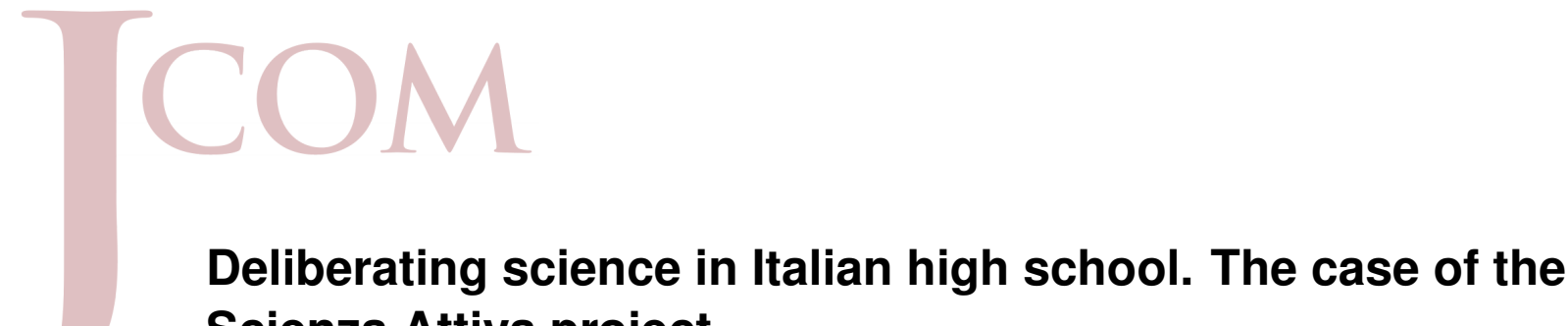 Scienza Attiva project
}

\section{Federica Cornali, Gianfranco Pomatto and Selena Agnella}

\begin{abstract}
This paper provides an analysis of the implementation and the outcomes of Scienza Attiva, an Italian national project for secondary school students, that makes use of deliberative democracy tools to address socio-scientific issues of great impact. The analysis has required a mixed method including surveys of students' pre- and post-project opinions, focus groups and interviews with students and teachers. The results from this evaluation study provide evidence that the project improves students' understanding of socio-scientific issues, strengthens their awareness of the importance of discussion and positively influences interactions in the classroom.
\end{abstract}

Keywords

Citizen science; Public engagement with science and technology; Science education

Introduction

There has been growing recognition of the importance of science education in recent decades. A large variety of goals have been attributed to it, ranging from the development of individual skills — such as logical reasoning, critical thinking, problem solving, decision making and subjective empowerment [Bybee, 1987; Aikenhead, 1992; Solomon, 1993] - to the training of a competent work force [Moore, 1991; Wirth, 1991] and the development of socially responsible citizenship at the national [Cross and Price, 1999] and global levels [Knain, 1999; Kolstø, 2000]. This growing recognition, accompanied by calls from government agencies and international bodies [UNESCO, 1983; AAAS, 1989; The Royal Society, 1985; Parliament and Council, 2006], has led to innovations in science teaching in many countries. These innovations center chiefly on revising school curricula, trying out new teaching methods and improving teacher training. Science education, in fact, does not only aim to transmit the notions, theories and terminology needed to understand scientific issues; it also aims to make students able to comprehend the impact of science and technologies on daily life, to reflect critically and thus make informed decisions. Nevertheless, a traditional deductive way of teaching often prevails at school, based on the explanation of theories and concepts followed by examples and exercises. Moreover, school programs and textbooks are unlikely to devote much space to analyzing the social, economic and cultural conditions in which scientific knowledge develops, or the explicit and implicit values involved in scientific research and socio-scientific controversies.

In order "to get young boys and girls more interested in science by giving each pupil the basic knowledge they need to act as responsible citizens in the face of 
scientific choices" [European Commission, 2002, p. 11], several projects that emphasize the social dimension of science and promote the study of the relationship between science, technology and society have also been started in Italy. We performed an evaluative analysis of one of these projects, called Scienza Attiva: a national project for secondary school students that has been interconnecting science and schools for almost a decade to build students' skills in finding information, doing research, learning independently, and discussing complex issues from a deliberative perspective.

This article presents the Scienza Attiva case-study, in order to provide a basis for assessing the project's implementation and results. Specifically, this study sets out to determine whether the procedures called for by the theoretical framework namely the deliberative paradigm - were followed, and to gather evidence on whether the expected outcomes were achieved.

\section{About Scienza \\ Attiva: structure, goals and theoretical background}

Scienza Attiva (hereafter SA) engages high school students aged 14-18 and teachers in a program of activities (mixing formal and informal learning) which aims to raise the attractiveness of science education and to make STEM (Science, Technology, Engineering and Math) more compelling by giving the students a key role in the learning process, actively involving them in building their own knowledge through close interaction with experts and making them "act science".

The SA project is designed and implemented each year by the Agora Science Inter-University Center with the support of foundations, institutions and universities. It brings together students, teachers and researchers in an exercise of scientific citizenship, and aims to emphasize the teacher's importance as mediator and reflective practitioner, to provide opportunities for debate and discussion among peers, to stimulate an open and constructive dialog between students and scientists, and to urge students to consider controversial issues and identify possible solutions and future scenarios. Every year, SA offers participants the opportunity to learn, to meet and share future scenarios on complex, topical scientific and technological issues. Each theme is associated with a panel of experts made up of university professors, researchers and industry experts. Panel members create information material (in different levels of detail and difficulty) and answer students' questions during the dialog stage on a voluntary basis.

The project started in academic year 2008/2009, when it dealt with energy and air pollution issues. Subsequent sessions addressed other issues: water, climate change, stem cells and nanotechnology, followed by food and agriculture in the special session for EXPO 2015. The next two years will tackle the issue of energy for the future.

For students, the project takes place during the school year, from November to April, and is organized in four scheduled stages. It makes use of deliberative democracy tools to address innovative scientific and technological topics of great social impact [Goodin, 2009; Grönlund, Bächtiger and Setälä, 2014]. SA organizes training meetings for teachers before the activities begin. Training covers deliberative democracy methods and the scientific aspects of the topics to be investigated. After attending training, and before starting the project in their 
classes, teachers have the chance to dialog with experts to clarify any aspect of the method and the scientific topic.

The proposed activities make the participants key players in the learning process, stimulating curiosity, creativity and critical thinking.

The SA deliberation process consists of four steps:

1. Prior knowledge: summary of what students know about the topic before the project starts.

2. Information: groups work both in the class and on the website to build a scientific knowledge of the selected topic.

3. Dialog with experts: group work and online discussion with experts, asking for clarification on the information they found while learning more about the topic and in order to hypothesize future scenarios.

4. Final proposals: on the basis of lessons learned from the documents, critical reflection and exchange of dialog, the classes - in an exercise in deliberative democracy — prepare scenarios and/or make suggestions.

Largely web-based, SA relates scientific research and education environments. The web platform (www.scienzattiva.eu) is the key instrument for providing information to increase interaction among participants. Students can find a wealth of material on the website: documents prepared especially for this project by researchers to help and instruct the students and provide tips and advice for their teachers. The students can dialog with the experts and ask questions through the website, talk with each other, share knowledge and experience. The basis of the deliberative process, however, evolves in the class where the peer group can debate, argue their point of view and settle controversies. Through an online poll, all classes participating in the project produce a synthesis of the proposals and a final document about the best proposals is submitted to scientists and institutions.

In the eight years of its life, the project has involved more than 20,500 students, 800 teachers and 300 researchers, each time creating a community that participated actively in the discussion of science, technology and society in our country: the researchers have tested RRI (Responsible Research and Innovation) practices, students have been encouraged to think critically, teachers have had the opportunity to try an alternative approach to teaching science, and lastly, the local political system and research institutions have been encouraged to listen to the youngest members of society and innovate accordingly.

Two theoretical frameworks guide SA: the field of deliberative democracy and the tradition of American pragmatist thought. Deliberative studies provided the first reference point: the idea that a structured interaction between citizens and experts on a relevant issue can produce opinion change and positive sum solutions. In order to achieve these results, it is essential that the process include an extensive informative phase, and that professional facilitation be provided to ensure participants can express themselves equally [Habermas, 1996; Bohman, 1996; Gutmann and Thompson, 1996; Elster, 1998; Niemeyer and Dryzek, 2007; Kadlec, 2008; Elstub, 2010; Mansbridge et al., 2010]. 
The notion of reflexivity advanced by Dewey [1910] was the second reference point for the SA project. Reflexivity should not be considered as a sort of abstract and solitary activity carried out by individuals; rather, it is a kind of real interaction that through the analysis and interpretation of empirical evidence can produce useful change in problematic situations. A more recent literature stemming from this basis focuses on the fundamental epistemic distinction between scientific and practical knowledge [Schön, 1983; Weick, 1995]. Scientific knowledge aims to produce generalizations based on cause and effect relationships and is in the hands of experts. Practical knowledge belongs to everyone and derives from continuous interaction with reality. From this perspective, both kinds of knowledge are crucial and society needs their interaction, especially on issues that are characterized, like many topics in science, by ethical dilemmas, controversies and uncertainty.

Both of these traditions of thought are very much a part of the fields of Science-Technology-Society (STS) and Public Engagement with Science and Technology (PEST), which for decades have engaged in the study of scientific knowledge held by members of the lay public, their opinions and attitudes regarding science, and their viewpoint on decision-making processes related to techno-scientific issues [Suerdem et al., 2013]. In recent times, there has been an increased awareness of the significance of public participation in socio-political discussions about scientific issues of collective importance. On the one hand, this democratizes decision-making, while on the other hand it provides a useful contribution, as the lay public's knowledge may be relevant for the co-production (together with scientists, politicians, stakeholders and other experts) of valid knowledge [Epstein, 1995; Wynne, 2001]. Nevertheless, constructing a relationship model in which different actors interact in public arenas is neither simple nor straightforward: the diversity of languages, misunderstandings and mutual distrust may stand in the way of fruitful dialog. For these reasons, it is important that young people can gain experience in public engagement while still at school.

The SA project's complex structure allows students to experience the three public engagement mechanisms indicated by Rowe and Frewer [2005]: the public communication mechanism, the public consultation mechanism and the public participation mechanism. Students in fact receive the communication message of scientists and experts; express their own point of view and their opinions; enact dialog and negotiation in order to reach shared positions. Addressing scientific issues in the appropriate social and cultural context allows students to highlight the values implicit in the practice of scientific research and involves analyzing the social conditions in which knowledge is produced and the consequences resulting therefrom. In particular, this makes it possible to take students' knowledge, needs and expectations into account by encouraging them to examine and discuss controversial techno-scientific issues - from urban pollution to genetic modification, the use of nuclear power generation and stem cells - to learn the sciences by dealing with problems.

The benefits of such an approach are primarily shown in students' increased interest in the sciences [Bennett, Lubben and Hogarth, 2007], better results achieved in terms of learning and understanding issues [Lubben et al., 2005], and in the development of critical thinking skills and social responsibility [Gilbert, 2006; Ryder, 2002]. 
Project evaluation

method

The evaluation framework

The present study aims to assess the seventh session (2014-2015) of the SA project. In this academic year, over 4,200 students, 160 teachers and 68 scientists participated in the project, dealing with issues associated with food, nutrition and agriculture, in particular with GMOs, environmental sustainability, innovation in the food chain and several other topics.

Since 2008, a number of different evaluation methods have been used, depending on the number of participants and the project's evolving characteristics. We chose to pursue two objectives: investigating the dynamics that developed during project implementation, and determining the project's outcomes.

To carry out the evaluation study, we chose a combination of standardized procedures (such as questionnaires) and non-standardized procedures (such as in-depth interviews and focus groups) in order to meet the need for valid, in-depth interpretations of a highly complex project.

The mixed method included: 1 . specific surveys of students' pre- and post-project opinions, as suggested by modern deliberative democracy studies to test changes; 2. a series of focus groups with students; 3 . a series of focus groups with teachers; 4. interviews with teachers.

The pre-SA questionnaire consisted of general questions (students' year of birth, sex, school attended, etc....), while the post-SA questionnaire asked students to make judgments about the project that had just ended. Both questionnaires also had a number of identical batteries to tap the student's opinions and attitudes concerning socio-scientific issues addressed during the project, and thus compare opinions before and after SA. Each battery consisted of a series of statements with which students were asked to indicate their degree of agreement on the following scale: 1 Strongly agree / 2 Somewhat agree / 3 Neither agree nor disagree / 4 Somewhat disagree / 5 Strongly disagree. We thus used classic five-point Likert scales, which are believed to provide an approximation of cardinality, as response categories are equidistant along the continuum of the property to be captured.

There are numerous well-argued criticisms of the assumption of equidistance [Galtung, 1967; Jamieson, 2004]. Nevertheless, we adopted this scaling technique here, as it is a universally known and easily understood method for survey collection. We therefore felt it was the best tool for collecting information quickly and efficiently from a group of young students. We paid particular attention to battery construction. Students were asked to express their agreement or disagreement with statements that had previously been tested in other surveys [Eurobarometer, 2010] and were deemed relevant to our survey, as well as to statements formulated ad hoc using simple language, presenting a single cognitive object and avoiding double negatives. An attempt was made to overcome the recurrent problem of agreement bias by avoiding social desirability issues, while some of the items in the questionnaire were negatively worded and reverse scored to eliminate or reduce response set.

The pre-SA questionnaire was administered electronically to all students between September and October 2014, before the project's starting date. The post-SA 
questionnaire was administered electronically from April to May 2015. It was expected that the response rate would be low, as the SA organizing committee requested that questionnaires be non-mandatory. In fact, only 280 students out of a total of 4,200 participants filled in both the pre- and post-SA questionnaires. This high level of self-selection, however, is quite common for a voluntary survey and was not an obstacle to the investigation, as the number of completed questionnaires was sufficient for analysis.

Focus groups involved a set of classes that were particularly active in the project, from different geographical areas and types of secondary school. Specifically, six student focus groups and three teacher focus groups were held in three cities (Torino in the north, Piacenza in central Italy and Salerno in the south). Each student focus group involved an entire class, numbering from 18 to a maximum of 30 students. The three teachers' focus groups each involved from 4 to 10 teachers.

The focus groups and the interviews focused on the following topics: the structure of the process carried out by the class, the interest in the selected issues and the classroom hours devoted to them, the sequence of work by subgroups and by the entire class, the relational aspects, the class "climate" during the project, the level of cooperation vs. conflict; the dynamics of relationships with teachers and with the experts. The text of all focus groups and interviews were coded using the following categories: interaction in the classroom; role of the teacher; interaction with scientists; online interaction; phases of project. The text were individually coded by two of us; the results were identical for each category in more than the $90 \%$ of the cases and the analysis considered only the passages coded in the same way.

Table 1 summarizes the evaluation framework we adopted, highlighting the evaluation issues and the tools for each dimension.

Two goals were pursued in evaluating project implementation: first, to measure student satisfaction, given that SA adopts an innovative approach that has been little used in Italian schools; second, to gather evidence on adherence to the procedural canons of the deliberative paradigm. Our evaluation questions were as follows:

- Did the class work in groups of students? To what extent did the students think the interaction was useful? To what extent did the students use argumentation? (Evaluation Issue 1.1);

- To what extent were the teachers able to act as facilitators? (Evaluation Issue 1.2);

- To what extent were the students satisfied with the experts? How did the students interact with them? (Evaluation Issue 1.3);

- Did the students interact intensively on line? (Evaluation Issue 1.4);

- To what extent were the students satisfied with the different stages of implementation? (Evaluation Issue 1.5).

In evaluating project outcomes, our aim was to determine whether SA produced the effects that according to the literature derive from deliberation: changes in the 
Table 1. Evaluation framework of Scienza Attiva project.

\begin{tabular}{|c|c|c|}
\hline Dimensions & Evaluation Issues & Tools \\
\hline $\begin{array}{l}\text { 1. Implementation } \\
\text { of SA }\end{array}$ & $\begin{array}{l}\text { 1.1 Interactions in the classroom } \\
\text { 1.2 Role of the teacher } \\
\text { 1.3 Interaction with scientists } \\
\text { 1.4 Online interaction } \\
\text { 1.5 Phases of project }\end{array}$ & $\begin{array}{l}\text { Post-SA student survey } \\
+ \text { focus groups }+ \\
\text { teacher interviews }\end{array}$ \\
\hline \multirow[t]{3}{*}{$\begin{array}{l}\text { 2. Outcomes } \\
\text { of SA }\end{array}$} & $\begin{array}{l}2.1 \text { Personal relationship with } \\
\text { the world of science } \\
2.2 \text { Relationship between science } \\
\text { and society } \\
2.3 \text { Relevance of the discussion } \\
\text { of socio-scientific controversies } \\
\text { 2.4 Self-confidence }\end{array}$ & $\begin{array}{l}\text { Pre- and post-SA } \\
\text { student surveys }\end{array}$ \\
\hline & 2.5 Interactions in the classroom & $\begin{array}{l}\text { Pre- and post-SA student } \\
\text { surveys }+ \text { focus groups }+ \\
\text { teacher interviews }\end{array}$ \\
\hline & 2.6 Effectiveness of method & $\begin{array}{l}\text { Post-SA student } \\
\text { survey }\end{array}$ \\
\hline
\end{tabular}

opinions, personal attitudes or relations among persons who took part in the process. To determine whether students' opinions changed as a result of participating in the SA project, the questions regarding students' orientations and attitudes in the several areas (as well as relationship with the world of science; relationship between science and society; relevance of the discussion of socio-scientific controversies; interactions in the classroom) were identical in both the initial and final questionnaires. Our evaluation questions were as follows:

- Has the students' inclination towards scientific studies changed and, if so, to what extent? What about their interest in science? Their judgement on the usefulness of scientific studies? Their propensity towards scientific professions? (Evaluation Issue 2.1).

- Has the students' opinion on the role of scientist changed and, if so, to what extent? What about their opinion of the capacity of lay citizens to take part in decisions on health and the environment? On the potential for improving society through scientific research? On the threats to fundamental values by science? On the decision-making process regarding decisions that have effects on everyone's lives? (Evaluation Issue 2.2).

- Has the students' opinion on the importance of informed discussion changed and, if so, to what extent? (Evaluation Issue 2.3).

- Has the students' self-confidence in their capacity to reflect on scientific issues changed and, if so, to what extent? (Evaluation Issue 2.4).

- Has the class changed in terms of freedom of expression, in the capacity to discuss or in internal conflict and, if so, to what extent? (Evaluation Issue 2.5). 
Obviously, SA's purpose is not to manipulate individual preferences, but to raise awareness about socio-scientific issues, stimulating dialog and democratic debate. From this point of view, the change in opinions - or the change in their intensity - testifies to the effectiveness of the deliberative process: after students were informed and participated in the discussion, their opinions are different from those they expressed earlier [Fishkin, 2009].

Regarding the outcome of SA, we also asked students to evaluate the effectiveness of the method based on a comparison between what happened during SA and their experience with traditional teaching methods. Our evaluation questions were as follows: Do students think that SA is better or worse than traditional methods? Do students consider that it is useful to extend the use of the SA method? (Evaluation Issue 2.6).

The overall evaluation of SA is based on the concordance and consistency between qualitative and quantitative evidence we gathered and the statistical significance of changes measured through pre- and post-SA student surveys $(N=280)$.

\section{The limitations of the study}

The SA Project has expanded significantly over the years: at the beginning it was a local project, whereas it is now a national project. As the project developed, its organizational procedures have changed, and the SA steering committee has found it necessary to evaluate both the project's implementation and its results. At the same time, the steering committee has not given us free rein in evaluating the SA Project. We were asked to design and implement an evaluation framework respecting two main limitations: first, evaluation had to interfere as little as possible with teachers' work and the activities of experts and students in order not to jeopardize the implementation of the project itself, which is based on a complex combination of voluntary participation by teachers, voluntary work of experts and students' extracurricular activities; second, as evaluation had to be carried out with limited resources, it was not possible to create a control group. This in turn made it impossible to reward, albeit symbolically, the students and teachers who took part in the study, as is commonly done in evaluation research to avoid low response rates.

On the whole, these limitations were not an impediment to effective evaluation. Nevertheless, the results of the evaluation of outcomes (Dimension 2) must be considered with caution and a few caveats, as the study did not take the form of an impact evaluation.

The changes found in students' inclinations and opinions (Evaluation issues 2.1; $2.2 ; 2.3$ and 2.4) as well as in interactions in the classroom (Evaluation issue 2.5) cannot be considered the net effect of the SA project. They are based on a pre-post comparison of the participants without a control group and are thus the "gross" effect of the SA project. This means that part of the changes detected in our analysis may be due to additional intervening variables that we were unable to identify. Though several pieces of evidence suggesting that the SA project had an effect on these issues were collected in the interviews and in the focus groups, the present study was not able to measure the impact of the SA project alone. 
The method's effectiveness (Evaluation issue 2.6) was analysed in the light of students' perceptions. Though the individual and anonymous survey we adopted guarantees that students' answers are sincere, their perceptions could be affected by a lack of extensive and well-founded knowledge of teaching methods.

\section{Quantitative evidence on the implementation process of SA}

\section{Class interaction among students}

First of all it, was considered important to obtain information regarding interactions among students during the project. This is especially significant, since the method proposed by SA is based precisely on exchanging views. Through their interaction, the project participants can learn, demonstrate their knowledge and test the effectiveness of their communication. In particular, we were interested in determining whether participatory methods were in fact applied when formulating proposals. This question can be answered affirmatively because the whole class, either working together or in subgroups, seems to have been the protagonist of the formulation process. $27.7 \%$ of students reported that "Individual proposals were developed mainly by individual students and then shared in class", while $48.1 \%$ said that "Each proposal was developed by independent subgroups and then shared in class". The percentage of those who say that proposals were suggested by a single student is low $(14.1 \%)$, while the percentage of students who claim that the teacher formulated proposals is minimal $(2 \%)$.

When asked to what extent they agreed with the statement "Interaction in the classroom was not profitable", the majority of students (54.5\%) reported that they disagreed strongly or somewhat, while $25.1 \%$ agreed strongly or somewhat. The remaining students did not know or had no precise opinion.

We then asked students to rate their satisfaction with the interaction, but this time referring to the interaction involved in formulating proposals and achieving a synthesis in the final stage. Here, the percentage of students who felt the interaction was fairly useful or completely useful was $66.6 \%$, while only $13.5 \%$ did not think it was useful. Not surprisingly, the vast majority of students $(82.4 \%)$ agreed with the statement, "The proposed arguments were valid and relevant to the topic".

\section{Role of the teacher}

The teacher undoubtedly has an important role in classroom interaction, both in stimulating dialog and ensuring that all students could express themselves. Regarding the teacher's role as facilitator, we then asked the students, first, whether they thought that the teacher had been able to relinquish his or her usual habits as an educator in order to act as a facilitator, and second, whether the teacher's performance as a facilitator had been satisfactory. For both questions, the majority of students responded favourably, with percentages of $57.9 \%$ and $63.2 \%$ respectively. Evidently, most students felt that the teachers were able to take on a role that was unfamiliar to them, and to do so with good results.

\section{Interaction with scientists}

The SA Project is also an occasion for interaction with the world of science, offering students the opportunity to dialog with scientists, in an exchange of questions and 
answers. This interaction - though certainly less direct than that experienced with peers in the classroom because it is completely mediated by electronic means was still viewed positively by students, who said they were mostly satisfied by the answers given by scientists [together, respondents reporting that they were completely satisfied and those who were fairly satisfied account for $64.8 \%$ of the total]. This result seems encouraging. All too often, interaction with scientists results in misconceptions and misunderstandings, due to conflicting epistemological frameworks, which consequently makes the public less likely to believe that involvement in participatory activities is effective and useful [Fischer, 2000; Garvin, 2001].

\section{Online interaction}

While almost all the students found the stage where they discussed the issues and formulated proposals to be quite absorbing, the same cannot be said of the subsequent stage. The process of identifying the points in common between similar projects was found to be less attractive: only a third of the students (30.3\%) claimed to have read all the proposals posted on the website, which is a necessary prerequisite for getting an overall picture of what other classes throughout Italy have done and then proceeding to make syntheses.

\section{Project stages}

The students were also asked to express their level of satisfaction with the different stages of the project. Stage II, "Information", was by far the favorite: $61 \%$ reported that it was very / extremely satisfying. The fact that students were not equally happy with the "Dialog with the experts" (Stage III is the one that garnered the least support: only $42.3 \%$ of the students said they were very / extremely satisfied) might give the impression that they favored a more traditional way of conveying knowledge, and that research and analysis of documents is preferred to interaction and discussion with experts. Other evidence, however, does not bear out this interpretation: more than half of the students (56.8\%) liked the stage that was perhaps the most innovative and unusual in a school setting: Stage IV "Final proposals".

\section{Qualitative evidence on the implementation process of SA}

\section{Class interaction among students}

The comments made in the focus groups do not allow us to express a judgment regarding the substantive quality of the deliberation that took shape in the classes. Nevertheless, they seem to indicate that the fundamental procedural rules of deliberation [Steiner, 2012] - involving the creation of a discussion that is open to opposing views and to reformulating proposals - were abided by. We give two of the comments by way of example:

"G.: At the beginning, everybody was divided on the basis of your interests, then three big subgroups were formed and we met several times in the afternoon, and everyone explained his proposal and after this interchange we revised it again and then we posted it" (Student focus group 2, Piacenza). 
"M.: The groups studied the topic they preferred and then discussed it, and then all the groups presented their work [...]

R.: Yes, at the end of each group's presentation, the others in the class had to say what according to them was wrong about the project" (Student focus group 1, Piacenza).

\title{
Role of the teacher
}

The facilitating role played by teachers also emerged in the focus groups. As the remarks quoted below indicate, several students were able to independently identify the traits that characterize the complex role of facilitation [Susskind, McKearnen and Thomas-Lamar, 1999; Landwehr, 2014], including a commitment to organizing the process and ability to manage dialog proactively, i.e., by acting as a stimulus and support, without making value judgments:

\footnotetext{
"V: The teacher helped us look for sources, or rather, in selecting sources. She made us able to identify which sources are reliable and which are not... to focus on the most relevant data [...] In this project the teacher was like us... she was at the same level we were and she helped us thanks to her experience... a sort of managerial experience" (Student focus group 2, Salerno) . "L.: (The teacher) was fundamental from the organizational point of view, but we developed the content of the project by ourselves" (Student focus group 3, Salerno).

"G.: The teacher wanted to make us as independent as possible; she tried not to interfere... she helped us if we needed it, but she tried to get us to do the work on our own" (Student Focus group 2, Piacenza).
}

For teachers, acting as a facilitator means adopting standards of judgment that differ from the usual one, and proceeding by trial and error. A concrete example is provided by a teacher who took part in the project two years in a row, and thus had the opportunity to reflect on the choice of "student-editors" or students (usually two per class) who support the teacher in performing as a facilitator and in some organizational activities:

\begin{abstract}
"I1: We took part in the project last year and it didn't go well. But we learnt from our mistakes [...] Last year we had two classes involved and I assigned the role of student editor to two very good pupils. But later I realized that you don't need a good student, but a good organizer. So this year I did that, you need somebody who can organize and motivate the group [...] otherwise the best students do everything themselves." (Teacher focus group, Salerno).
\end{abstract}

\section{Interaction with scientists}

Several comments made in the focus groups show that students possess a sophisticated, knowledgeable and structured capacity for interacting with scientific knowledge, which is accompanied by the development of a capacity for independent research. The reliability of sources, for example, is clearly addressed by this class: 
“D. C.: We used a lot of source material [...] we studied different texts and some classmates and I worked chiefly on this, and we ended up looking at thirty or forty research files.

E: The main problem is finding a reliable source, that has a scientific basis [...]

D.C.: They were mainly statistical data, but not exactly reliable" (Student focus group 2, Salerno).

In another case, students demonstrate that they turn to experts in order to complement and enhance the knowledge they gain from their studies, rather than to replace it:

"L. G.: At the beginning, we made a table with what we already knew about the topics and what we were interested in learning [...] after reading the documents, we met to see what we still wanted to know" (Student focus group 1, Piacenza).

As the following quote indicates, students ask the experts not only for specific technical knowledge, but also for contextualized opinions linked to their practical knowledge [Schön, 1983; Weick, 1995]:

“P.: The expert's personal opinion. An expert is a person, even before he's an expert, he's a human being who goes shopping like everybody else, and an expert looking at a product knows more than we do, knowing which products he chooses and why he chooses then helps us understand what we should do" (Student focus group 1, Salerno).

\section{Online interaction}

The focus groups confirmed that the project's last stage, which involved integrating proposals from different classes on the online platform and voting on the best proposals, was the most problematic. Students much preferred face-to-face interaction to interaction at a distance. Even in the few cases in which proposals from multiple classes were integrated, remote interaction was not sufficient and was complemented by in-person meetings:

"S. P.:[...] we received several votes and two other classes asked us to combine our proposal with theirs. We rejected the first, aside from the distance between the schools, it was really different from ours, while the other was very similar and so we decided to meet in the afternoon and then we drew up a final proposal and then if you consider that we had a lot of trouble at the beginning, it's a good result at the end" (Student focus group 2, Piacenza).

"R.: We combined our group with a class close to us in this school [...] a teacher for each class managed the project and had us meet, we found pros and cons and we reached an agreement on how to change the proposal, it was already similar, there were some points that were deleted and others that were added" (Student focus group 1, Piacenza).

Participation was also low in the voting stage. In this case there was probably a more contingent reason: the classes felt that they were part of a competition and thus were reluctant to vote for other classes' proposals, for fear of giving them an advantage: 
"C.: If I vote for the proposal of another class I know that I increase the probability that that class will win... so we were not particularly motivated to vote..." (Student focus group 3, Salerno).

\section{Quantitative evidence on the outcomes of SA}

\section{Personal relationship with the world of science}

Regarding this first area, a battery of 5 items about "Personal relationship with the world of science" was administered to tap students' inclination for the study of scientific subjects ("I understand scientific topics and learn about them easily"); their level of interest in this connection ("I don't take an interest in scientific subjects outside of school"); judgment about the usefulness of this type of study ("When I finish school I will have many opportunities to use my scientific knowledge"), as well as their propensity to go into a scientific profession ("I do not intend to continue to study science after my diploma"; "I'd like to pursue a profession in science"). To compare opinions before and after SA, we used a paired sample t-test procedure, assuming normality of the difference between scores and independence of observations. Before carrying out these calculations, we proceeded to deflate the data matrix to detect speeding, straightlining and other signs of careless responses, which mainly consist of assigning scores in repeated patterns. The test results indicated significant changes in two pairs (pre-post) of statements, out of the five in the battery. For Pair 1, at the end of the project the students $(N=275)$ showed statistically significant greater agreement about understanding scientific subjects readily; pre-SA $(M=-1.17, S D=1.09)$ and post-SA $(M=-1.30, S D=.94), t(274)=2.17, p=.03$.

The same is true of Pair 3: students $(N=259)$ showed a greater degree of agreement about opportunities to use scientific knowledge when they will end up school in the final questionnaire $(M=-1.45, S D=.94)$ than in the initial questionnaire $(M=-1.20, S D=1.17), t(258)=3.80, p=.00$. A look at the standard deviations also shows that while opinions were more dispersed in the initial questionnaire, in the final one the students are not only in greater agreement with the proposed statement, but they are also in greater agreement among themselves.

\section{Relationship between science and society}

The battery designed to tap students' opinions on the relationship between Science and Society required students to indicate their degree of agreement with the following statements: "Scientists do not do enough to inform the public about science and technology"; "The general public does not have the skills needed to participate in decisions affecting the environment and health"; "Society can be improved only through advances in science and technology"; "Contemporary science threatens fundamental values such as the sanctity of human life and nature"; "Responsibility for decisions that affect everyone cannot be left only to scientists and politicians". There was a significant change of opinion in only one case, i.e., regarding the statement "Responsibility for decisions that affect everyone cannot be left only to scientists and politicians" (Pair 5), where students' agreement rose significantly in the final administration $(N=258)$; pre-SA $(M=-1.30$, $S D=1.15)$ and post-SA $(M=-1.72, S D=0.92), t(257)=5.35, p=.00$. 
It is interesting to note, however, that the only other case where the change in opinion was statistically significant, albeit only in trend, regarded the statement "Society can be improved only through advances in science and technology" (Pair $3)$, again with an increase in agreement; pre-SA $(M=-.58, S D=1.11)$ and post-SA $(M=-.73, S D=1.19), t(258)=1.87, p=.06$.

We can thus suppose that students are basically not 'technocrats', but 'technophiles'.

\section{Relevance of the discussion of socio-scientific controversies}

As regards the relevance of discussing socio-scientific issues, the students were administered one battery of 5 items about the goals that can be achieved through such discussion. Students were asked to rate the importance of discussion of socio-scientific controversies in order to "Increase my knowledge"; "Form my own opinion", "Convince others of my opinion", "Formulate joint proposals", "Change the situation". The only statistically significant change concerns the increase in agreement with the statement of Pair 2 "Form my own opinion"; pre-SA $(M=-.69, S D=.63)$ and post-SA $(M=-.58, S D=.65), t(270)=2.15, p=.04$.

The intention to intervene in a situation, changing it or persuading people with other opinions or making proposals, did not change significantly. The same was true of discussion in order to increase one's own knowledge. This latter result provides partial confirmation of earlier findings, e.g., the increase in satisfaction with the "Information Stage". Though students are certainly interested in increasing their knowledge, they probably believe that this can be more readily achieved through traditional pathways, such as the analysis of documents and study rather than through discussion (which by contrast is useful for forming opinions and judgments).

\section{Self-confidence}

Overall, the project was appreciated, with a clear majority of students who say they agree strongly or somewhat with the statement proposed in the post-questionnaire "Participating in the SA project has increased my capacity for reflection on scientific issues" (66.3\%).

\section{Interactions in the classroom}

Lastly, a battery of items repeated in the pre- and post-project questionnaires allowed us to check for changes of opinion about the interaction in the classroom, in particular concerning the following points: "All students feel free to express their opinion"; "We're not used to discussing problems of general interest together in the classroom"; "Students are not able to express their views effectively during discussion with teachers"; "A climate of dialog and understanding generally prevails among students "; "Leaders emerge during group discussions"; "Conflicts are common".

The paired sample t-test shows a tendentially significant change with a greater degree of agreement with the statement "A climate of dialog and understanding 
generally prevails among students" (Pair 4); pre-SA $(M=-1.02, S D=1.14)$ and post-SA $(M=-1.17, S D=1.13), t(272)=1.91, p=.06$. No significant change was found for the remaining statements.

\section{Effectiveness of method}

The post-questionnaire administered to students also asked them to express personal opinions about SA. In order to gauge their approval of the method proposed by the project, they were asked to compare it with the traditional teaching conducted in the classroom.

$80.1 \%$ of the students agree with the statement "The method proposed by the SA project is useful for exploring some extracurricular subjects", while $65.2 \%$ of the students agree with the statement "You could extend the method proposed by SA to certain parts of the school curriculum". By contrast, $39.4 \%$ of the students say they agree with the statement "The issues addressed in the project would be better treated with classical teaching methods: well-structured curriculum, trained teachers, and intensive individual study". Students thus show they appreciate a method that provides an opportunity to address issues close to their everyday life experiences, taking into account their needs, expectations and stock of knowledge, and encouraging them to take part in dialog and discussion. On the other hand, however, the high percentage of uncertain students (25\%) probably indicates that there is also a certain amount of appreciation for the traditional methods of teaching school.

\section{Qualitative evidence on the outcomes of SA}

\section{Interactions in the classroom}

The qualitative method's contribution to the outcome is necessarily limited. According to the literature, the best way to ascertain changes in individual opinion and self-confidence due to deliberative processes [Fishkin, 2009] is to ask a sample of participants to respond to the same questions before and after the deliberative process. Nevertheless, qualitative methods can be useful in gathering complementary evidence on relational aspects involving participants. We thus used focus groups and interviews to better investigate these aspects, seeking for confirmation or disconfirmation of the findings that emerged from quantitative analysis.

First of all, it is important to emphasize that none of the focus groups and interviews failed to confirm the strengthening of the climate of dialog and understanding among students resulting from SA that emerged from the pre- and post-SA questionnaires.

Secondly, a teacher interview and a focus group indicated that in a couple of cases, SA significantly strengthened internal cooperative relationships by acting as a team-building factor:

"This is a class that really joined together, this year I think it helped form the class group even more" (Teacher interview, Piacenza). 
"S.: Scienza Attiva helped us because we're not usually so united [...]

G.: It was constructive as a class.

D.: It was an important project because we learned to work all together, to deal with difficulties together, to make decisions together, [... ]" (Student focus group, Torino).

In Italy as elsewhere, the major role that science education can play in developing individual skills and democratic citizenship has attracted increasing attention [Cornali, 2015]. Nevertheless, discussing socio-scientific issues is still rather unusual in Italian schools. Scientific subjects are generally taught using a traditional strategy based on a sequence of theoretical knowledge, examples and exercises.

From this point of view, SA is an innovative project that is very much a part of the current trend towards educational programs which aim at putting science in context and promoting links between science, technology and society. Such programs involve a genuine renewal of the curricula and teaching practices, offering new content and new study materials. Examples of the most significant programs include the initiatives promoted by the socio-scientific issues research movement that offers a way to explore the nature of science and the relationship between science and society in dealing with contemporary socio-scientific controversies [see, for example, Kolstø, 2000; Albe, 2008].

Several authors speak of the need for a "socio-scientific issues education", envisaged as a way of considering "how controversial scientific issues and dilemmas affect the intellectual growth of individuals in both personal and societal domains" [Zeidler et al., 2005, p. 361]. According to this perspective, students are considered full citizens, and not merely budding citizens [Barrue and Albe, 2013]. They, like adults for that matter, acquire the capacity for reflection, critical thinking, decision making, and to foster moral and ethical development by opportunities to become involved as active citizens. These considerations suggest that curricula using such issues provide an environment where students become engaged in discourse and reflection. Recent cases concern students' involvement (with success) in discussing issues such as, for example, environmental dilemmas [Hogan, 2002], human genetic engineering [Zohar and Nemet, 2002], and animal experimentation [Simonneaux, 2001].

In Italy, use of socio-scientific issues and the deliberative approach to science education is highly sporadic, despite the many benefits extolled in the international literature. For these reasons, we can affirm that SA is a particularly interesting case study since it develops a interdisciplinary approaches between science education and public engagement and produce a commingle that can innovate Science Communication view in school contest. In SA project science is communicated among scientists and other groups by dialogue, sometimes to find out how science could be more effectively disseminated, sometimes for consultation on specific applications. The communication model that underlies the dialogue is the consultation. The public's opinions are sought by various means, with a view to redefining messages or negotiating about applications. The engagement is a fixed point of this, were there is a stronger emphasis on how publics express concerns, raises questions and helps to set the agenda for science communication and, 
eventually, for science. In those contexts, scientists are called on to open science-in-the-making for public scrutiny [Trench, 2008b]. Obviously the project mixed a simulation of participatory setting and educational objective, respecting the RRI values. The web tool chose to facilitate the opening of science to public view. The pervasive use of internet communication for public communication creates opportunities for more interactivity between scientists and students. It also permits public access to 'backstage' conversations between scientists, including the student in negotiate uncertainties in science [Trench, 2008a].

As an evaluation of the project that highlights the strengths and weaknesses, it is useful not only in order to improve the project itself but also as a means of disseminating the project's method and procedures. Because of the project's complexity, however, evaluation proved to be a challenging task. In fact, SA lasts for almost the entire school year (November to May) and combines heterogeneous activities. It includes face-to-face interactions, which take place in the traditional classroom setting, with interactions that take place in a virtual space formed by the web platform. It also unfolds in a sequence of stages that call for many different skills, ranging from reading and understanding scientific texts to formulating relevant questions, and from identifying reliable sources to preparing proposals and future scenarios.

With regard to the implementation of project, empirical evidence suggests that the SA process adhered to the fundamental canons of the deliberative paradigm. In particular, results of questionnaires, in-depth interviews and focus groups enable us to conclude that almost all students participated actively, or at least the vast majority. Obviously the large number of participants does not guarantee that the process was fair and effective, but there are other elements which would confirm that this will be achieved. At the first, most of the students in the classes that were involved participated actively in developing proposals, which in only a few cases were the result of work by individual students or the teacher. Secondly, teachers did in fact act as facilitators, a role that was unusual for them but was generally recognized and appreciated by students. Lastly, the interaction with experts was also considered satisfactory on the whole, and the focus groups testified that in some cases the students explored the experts' practical knowledge, revealing a particularly complex and mature approach to science. These findings indicate that the classes involved in the project generally showed commitment and interest in their work, regardless of the intrinsic value of the content of the final proposals developed by the students, which we did not set out to evaluate.

In this positive picture, online interaction between classes and voting on proposals emerge as more problematic, due to a low rate of participation. Students seem to prefer face-to-face interaction to interaction online. Though this may be surprising given the well-known propensity of digital natives for social networks, it should be noted that the debate revolving around on-line deliberation in the international literature is still far from settled: on-line techniques are an opportunity to involve more people in deliberation, but at the same time pose specific problems that have not been yet been unequivocally resolved [Strandberg and Grönlund, 2014].

Consequently, the difficulties encountered in the on-line stage of SA were not such as to justify a negative evaluation of the project on the whole, also considering that the online environment is often ill-suited to proposing and discussing highly complex issues. 
In our view, students' preference for face-to-face relationships over virtual relationships underscores the importance of the facilitator's role. In the exchanges that take place online, this role is lost, and with it the stimulus, mediation and support for the convergence process, all of which are decisive for the success of deliberative practice. Teachers are thus a key element in implementing the SA project: starting from their own enthusiasm for the initiative, they propose it to the class and monitor its progress for the entire school year. Their strong motivation and the ability to choose the most suitable staff (student editors) is essential for bringing the project to fruition. So it is no coincidence that, of the 120 classes where we collected questionnaires, many (43) were conducted by teachers who had already participated in at least one session of the project in the past.

With regard to the outcomes, there were a number of statistically significant changes in the opinions of students who took part in the project. Pre-post analysis showed that participating students were more confident of their ability to understand scientific issues, and more convinced of the usefulness of scientific knowledge and of the need to take part in policy-making, believing that decisions should not be monopolized by experts and political actors. Students also felt that the classroom climate had been improved by an increased capacity for dialog and mutual understanding. These results are positive, but caution is necessary given that, as explained in the methodological section of the article, external intervening variables could have played a role.

The analysis also found that there is some discrepancy among students about the method's effectiveness. The contrasting views expressed by the students show how difficult it is to introduce participatory science communication activities in the formal educational setting, and that the two approaches - that of education / training and that based on discussion / participation - should not be at odds with each other, but must be combined and concurrent.

This quali-quantitative analysis provides several pointers on how to improve the Scienza Attiva project. In particular, to increase student participation in the project, it is recommended that future sessions propose more hot socio-scientific topics, which provide students with food for thought and allow them to feel responsibility for working on a topic that is both current and important for their future. Second, the SA web platform should be provided with more dynamic tools that are in line with young people's habits. An app, for example, would make the project easily accessible also via mobile phone outside the school setting. It was also found that there is a clear need for more face-to-face interaction with both class groups (from different regions and institutions) and with experts. We recommend adding some live events to the project schedule to facilitate personal interaction. For classes in the same school, for instance, some discussion sessions should be held during the project, and schools should be provided with support in delivering lectures and discussions with experts.

Though it was observed that the students were satisfied with the amount of time scheduled for the various stages of the project, certain aspects should be optimized. For example, the prior knowledge step could be shortened to allow more time for the creative stage of planning new proposals, which the students appreciated and found more interesting. 
Furthermore, students should be assisted in the final proposal step by a panel of teachers and experts to make it more stimulating and motivating.

This article presents an evaluative study of SA, a project conducted in Italian high schools that adopts the deliberative perspective. The study focuses on two aspects: the dynamics that took shape during the implementation of the project and the resulting outcomes, and sought to determine whether these dynamics and changes were consistent with the expectations raised by the theoretical framework and similar initiatives elsewhere in the world.

The main results - derived from a mixed-method evaluation design that combined standardized procedures (such as questionnaires) and non-standardized procedures (such as in-depth interviews and focus groups) - show that the canons of the deliberative paradigm can be correctly implemented even in a school setting. Indeed, the school is a particularly suitable environment since its institutional purposes are to spread critical knowledge and train students for active citizenship. In fact, the outcomes of the SA project demonstrate that introducing this practice improved students' understanding of socio-scientific issues, their interaction in the classroom, and their awareness of the importance of discussion in forming an opinion.

Despite the limitation of the study we presented and discussed in the detail in the methodological section of the article, the findings we have presented here encourage the prospects of adopting a deliberative approach to science education even in a country such as Italy with little prior experience with such initiatives, and of achieving positive results in strengthening the public's scientific knowledge and the deliberative skills that are crucial to democratic citizenship [Parkinson and Mansbridge, 2012].

Aikenhead, G. S. (1992). 'Logical Reasoning in Science and Technology:: An Academic STS Science Textbook'. Bulletin of Science, Technology \& Society 12 (3), pp. 149-159. DOI: 10.1177/027046769201200305.

Albe, V. (2008). 'Students' positions and considerations of scientific evidence about a controversial socioscientific issue'. Science $\mathcal{E}$ Education 17 (8), pp. 805-827. DOI: $10.1007 / \mathrm{s} 11191-007-9086-6$.

American Association for the Advancement of Science (AAAS) (1989). Science for all Americans. A Project 2061 report on literacy goals in science, mathematics, and technology. Oxford, U.K.: Oxford University Press.

Barrue, C. and Albe, V. (2013). 'Citizenship Education and Socioscientific Issues: Implicit Concept of Citizenship in the Curriculum, Views of French Middle School Teachers'. Science E Education 22 (5), pp. 1089-1114. DOI: $10.1007 / \mathrm{s} 11191-012-9571-4$.

Bennett, J., Lubben, F. and Hogarth, S. (2007). 'Bringing science to life: A synthesis of the research evidence on the effects of context-based and STS approaches to science teaching'. Science Education 91 (3), pp. 347-370. DOI: 10.1002/sce. 20186.

Bohman, J. (1996). Public deliberation: Pluralism, complexity and democracy. Cambridge, MA, U.S.A.: MIT Press.

Bybee, R. W. (1987). 'Science education and the science-technology-society (S-T-S) theme'. Science Education 71 (5), pp. 667-683. DOI: 10.1002/sce.3730710504. 
Cornali, F. (2015). 'Scienziati a scuola. La comunicazione della scienza nei contesti dell'istruzione formale'. In: Apriti scienza. Il presente e il futuro della comunicazione della scienza in Italia tra vincoli e nuove sfide. Ed. by S. Scamuzzi and G. Tipaldo. Bologna, Italia: il Mulino, pp. 177-203.

Cross, R. T. and Price, R. F. (1999). 'The social responsibility of science and the public understanding of science'. International Journal of Science Education 21 (7), pp. 775-785. DOI: $10.1080 / 095006999290435$.

Dewey, J. (1910). How we think. Boston, MA, U.S.A.: D.C. Heath \& Company.

Elster, J., ed. (1998). Deliberative democracy. Cambridge, U.K.: Cambridge University Press.

Elstub, S. (2010). 'The Third Generation of Deliberative Democracy'. Political Studies Review, pp. 291-307. DOI: 10.1111/j.1478-9302.2010.00216.x.

Epstein, S. (1995). 'The Construction of Lay Expertise: AIDS Activism and the Forging of Credibility in the Reform of Clinical Trials'. Science, Technology $\mathcal{E}$ Human Values 20 (4), pp. 408-437. DOI: 10.1177/016224399502000402.

Eurobarometer (2010). Special Eurobarometer 354. Wave 73.5. Food-related risks. Brussels, Belgium: TNS Opinion \& Social.

European Commission (2002). Science and society action plan. Luxembourg: Office for Official Publications of the European Communities.

European Parliament and Council of the European Union (2006). Recommendation on key competences for lifelong learning. 18 December 2006 (2006/962/EC).

Fischer, F. (2000). Citizens, experts, and the environment: The politics of local knowledge. Durham, NC, U.S.A.: Duke University Press.

Fishkin, J. (2009). When the people speak: Deliberative democracy and public consultation. Oxford, U.K.: Oxford University Press.

Galtung, J. (1967). Theory and Methods of Social Research. London, U.K.: Allen \& Unwin.

Garvin, T. (2001). 'Analytical Paradigms: The Epistemological Distances between Scientists, Policy Makers, and the Public'. Risk Analysis 21 (3), pp. 443-456. DOI: $10.1111 / 0272-4332.213124$.

Gilbert, J. K. (2006). 'On the Nature of "Context" in Chemical Education'. International Journal of Science Education 28 (9), pp. 957-976. DOI: $10.1080 / 09500690600702470$.

Goodin, R. E. (2009). Innovating Democracy: Democratic theory and practice after the deliberative turn. Oxford, U.K.: Oxford University Press.

Grönlund, K., Bächtiger, A. and Setälä, M., eds. (2014). Deliberative mini-publics. Involving citizens in the democratic process. Colchester, U.K.: ECPR Press.

Gutmann, A. and Thompson, D. F. (1996). Democracy and disagreement. Cambridge, MA, U.S.A.: Harvard University Press.

Habermas, J. (1996). Between facts and norm: Contribution to a discourse theory of law and democracy. Cambridge, MA, U.S.A.: MIT Press.

Hogan, K. (2002). 'Small groups' ecological reasoning while making an environmental management decision'. Journal of Research in Science Teaching 39 (4), pp. 341-368. DOI: 10.1002/tea. 10025.

Jamieson, S. (2004). 'Likert scales: how to (ab)use them'. Medical Education 38 (12), pp. 1217-1218. DOI: 10.1111/j.1365-2929.2004.02012.x. PMID: 15566531.

Kadlec, A. (2008). 'Critical Pragmatism and Deliberative Democracy'. Theoria 55 (117), pp. 54-80. DOI: $10.3167 /$ th. 2008.5511704.

Knain, E. (1999). 'Sense and Sensibility in Science Education: Developing Rational Beliefs through Cultural Approaches'. Studies in Science Education 33 (1), pp. 1-29. DOI: 10.1080/03057269908560134. 
Kolstø, S. D. (2000). 'Consensus projects: teaching science for citizenship'. International Journal of Science Education 22 (6), pp. 645-664.

DOI: $10.1080 / 095006900289714$.

Landwehr, C. (2014). 'The role of impartial intermediaries in deliberative mini-publics'. In: Deliberative mini-publics. Involving citizens in the democratic process. Ed. by K. Grönlund, A. Bächtiger and M. Setälä. Colchester, U.K.: ECPR Press, pp. 77-92.

Lubben, F., Bennett, J., Hogarth, S. and Robinson, A. (2005). 'The Effects of context-based and Science-Technology-Society (STS) Approaches in the teaching of secondary science on boys and girls, and on lower-ability pupils'. In: Research Evidence in Education Library. London, U.K.: EPPI-Centre, Social Science Research Unit, Institute of Education, University of London.

Mansbridge, J., Bohman, J., Chambers, S., Estlund, D., Føllesdal, A., Fung, A., Lafont, C., Manin, B. and Martí, J. L. (2010). 'The Place of Self-Interest and the Role of Power in Deliberative Democracy'. Journal of Political Philosophy 18 (1), pp. 64-100. DOI: $10.1111 / j .1467-9760.2009 .00344$.x.

Moore, J. H. (1991). 'Science education, the national economy, and international competitiveness'. In: Science education in the United States. Ed. by S. K. Majumdar, L. M. Rosenfeld, P. A. Rubba, E. W. Miller and R. F. Schmalz. Easton, PA, U.S.A.: The Pennsylvania Academy of Science.

Niemeyer, S. and Dryzek, J. S. (2007). 'The Ends of Deliberation: Meta-consensus and Inter-subjective Rationality as Ideal Outcomes'. Swiss Political Science Review 13 (4), pp. 497-526. DOI: 10.1002/j .1662-6370.2007.tb00087.x.

Parkinson, J. and Mansbridge, J., eds. (2012). Deliberative systems: deliberative democracy at the large scale. New York, U.S.A.: Cambridge University Press.

Rowe, G. and Frewer, L. J. (2005). 'A Typology of Public Engagement Mechanisms'. Science, Technology \& Human Values 30 (2), pp. 251-290. DOI: $10.1177 / 0162243904271724$.

Ryder, J. (2002). 'School science education for citizenship: Strategies for teaching about the epistemology of science'. Journal of Curriculum Studies 34 (6), pp. 637-658. DOI: 10.1080/00220270210148434.

Schön, D. A. (1983). The reflective practitioner. How professionals think in action. New York, U.S.A.: Basic Books.

Simonneaux, L. (2001). 'Role-play or debate to promote students' argumentation and justification on an issue in animal transgenesis'. International Journal of Science Education 23 (9), pp. 903-927. DOI: 10.1080/09500690010016076.

Solomon, J. (1993). Teaching science, technology and society. Buckingham, U.K.: Open University Press.

Steiner, J. (2012). The foundation of deliberative democracy. Empirical research and normative implications. New York, U.S.A.: Cambridge University Press.

Strandberg, K. and Grönlund, K. (2014). 'Online deliberation: Theory and practice in virtual mini-Publics'. In: Deliberative mini-publics. Involving citizens in the democratic process. Ed. by K. Grönlund, A. Bächtiger and M. Setälä. Colchester, U.K.: ECPR Press, pp. 93-114.

Suerdem, A., Bauer, M. W., Howard, S. and Ruby, L. (2013). 'PUS in turbulent times II - A shifting vocabulary that brokers inter-disciplinary knowledge'. Public Understanding of Science 22, pp. 2-15. DOI: 10.1177/0963662512471911.

Susskind, L. E., McKearnen, S. and Thomas-Lamar, J. (1999). The consensus building handbook: A comprehensive guide to reaching agreement. Thousand Oaks-London: Sage. 
The Royal Society (1985). The public understanding of science. London, U.K.: Royal Society.

Trench, B. (2008a). 'Internet: Turning science communication inside-out?' In: Handbook of Public Communication of Science and Technology. Ed. by M. Bucchi and B. Trench. London, U.K. and New York, U.S.A.: Routledge, pp. 185-198.

- (2008b). 'Towards an Analytical Framework of Science Communication Models'. In: Communicating Science in Social Contexts. New models, new practices. Ed. by D. Cheng, M. Claessens, T. Gascoigne, J. Metcalfe, B. Schiele and S. Shi. Dordrecht, Netherlands: Springer, pp. 119-135. DOI: $10.1007 / 978-1-4020-8598-7 \_7$.

UNESCO (1983). Science for all. Bangkok, Thailand: UNESCO Office for Education in Asia and the Pacific.

Weick, K. (1995). Sensemaking in organizations. Thousand Oaks, U.K.: Sage.

Wirth, A. G. (1991). 'Issues in the reorganization of work: Implications for education'. Theory Into Practice 30 (4), pp. 280-287. DOI: $10.1080 / 00405849109543513$.

Wynne, B. (2001). 'Creating public alienation: expert cultures of risks and ethics on GMOs'. Science as Culture 10 (4), pp. 445-481. DOI: 10.1080/09505430120093586.

Zeidler, D. L., Sadler, T. D., Simmons, M. L. and Howes, E. V. (2005). 'Beyond STS: A research-based framework for socioscientific issues education'. Science Education 89 (3), pp. 357-377. DOI: 10.1002/sce. 20048.

Zohar, A. and Nemet, F. (2002). 'Fostering students' knowledge and argumentation skills through dilemmas in human genetics'. Journal of Research in Science Teaching 39 (1), pp. 35-62. DOI: 10.1002/tea. 10008.

Federica Cornali is researcher at University of Turin, Dept. Cultures, Politics and Society and she teaches Sociology in the degree programs of Educational Sciences. Her main research interests, which focus on the areas of sociology of education, include: citizenship education, school effectiveness and policy context, evaluation practices. E-mail: federica.cornali@unito.it.

Gianfranco Pomatto is contract professor in policy analysis at University of Turin, Dept. Cultures, Politics and Society. His main research interest include deliberative democracy, the communication of public policies and territorial conflicts.

E-mail: gianfranco.pomatto@unito.it.

Selena Agnella is a post doc fellow at the University of Estern Piedmont and member of the Interuniversity Cenre Agorà Scienza team, where she designs and organizes Public Engagement and Scienze Education projects. Her main research interests in STS include: scientific citizenship, researchers' practices of communication, Science Technology and Society relationship. E-mail: selena.agnella@uniupo.it.

How to cite

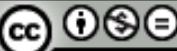

Cornali, F., Pomatto, G. and Agnella, S. (2017). 'Deliberating science in Italian high school. The case of the Scienza Attiva project'. JCOM 16 (01), A02. 